\title{
FAKTOR YANG BERHUBUNGAN DENGAN KEPEMILIKAN JAMBAN SEHAT DI DESA MALIKIAN, KALIMANTAN BARAT
}

\author{
Otik Widyastutik \\ Fakultas Ilmu Kesehatan, Universitas Muhammadiyah Pontianak \\ E-mail : otik@iuj.ac.jp, 08113061615
}

\begin{abstract}
The World Bank states that the 2010 data 22\% of Indonesian people has not had a sanitation facility (latrine). The existence of latrines in Indonesia, according to World Bank data in 2010 about 22\% of Indonesia's population does not have latrines. The coverage of national guard to urban areas with $79 \%$ and $49 \%$ for rural areas. Most of the sludge removal is using the river or dug wells which do not have the requirements of health latrine and contiminate the ground water. Based on the data obtained from the Health Center Community Mempawah Hilir in 2014 of 855 homes were inspected as many as 530 households, households have basic sanitation facilities such as latrines in the Health Center Community Mempawah downstream for 420 households or 79\%. This study aims to determine the relationship between the factors of income, knowledge, and attitude, with the ownership of latrines in Malikian, Mempawah Hilir. The research method uses observational design with cross sectional approach. The sample in this study are mothers who have children under five do not have latrines that sebayak 64 respondents. The sampling technique using random sampling. Statistical analysis using chi square test. Decision of research hypothesis testing based on the significance level of 5\% $(p=0.05)$ and confidence interval (CI) 95\%. The result show that there are relationship between income and the latrine ownership ( $p=0.037)$, knowledge $(p=0.037)$ and attitude $(p=0.037)$. The result shows no relationship between education ( $p=0196)$, and the role of health care workers ( $p=$ 1.000) with the ownership of latrines in the Malikian, Mempawah Hilir.
\end{abstract}

Keywords: Latrine, income, knowledge, attitude.

\begin{abstract}
Abstrak
Keberadaan jamban di Indonesia menurut data Bank Dunia tahun 2010 sekitar $22 \%$. Secara nasional, untuk daerah perkotaan yaitu $79 \%$ dan untuk daerah pedesaan 49\%. Sebagian besar pembuangan tinja masih dilakukan ke sungai atau mempergunakan sumur galian yang tidak memenuhi persyaratan sehingga mencemari air tanah. Berdasarkan data yang di peroleh dari Puskesmas Mempawah Hilir pada tahun 2014 dari 855 rumah yang dilakukan pemeriksaan sebanyak 530 rumah tangga, rumah tangga yang memiliki sarana sanitasi dasar berupa jamban di wilayah kerja Puskesmas Mempawah Hilir sebesar 420 rumah tangga atau 79\%. Penelitian ini bertujuan untuk mengetahui hubungan antara faktor penghasilan, pengetahuan, dan sikap, dengan kepemilikan jamban di Desa Malikian, Mempawah Hilir, Kalimantan Barat. Metode penelitian menggunakan rancangan observasional dengan pendekatan cross sectional. Sampel dalam penelitian ini adalah rumah tangga yang memiliki balita yaitu sebanyak 64 responden, di ambil dengan menggunakan random sampling. Analisis statistik menggunakan uji chi square. Hasil penelitian menunjukkan bahwa adanya hubungan penghasilan terhadap kepemilikan jamban $(p=0.037)$, pengetahuan $(p=0.037)$ dan sikap $(p=0.037)$. Hasil penelitian menunjukkan tidak ada hubungan antara pendidikan $(\mathrm{p}=0.196)$, dan peran petugas kesehatan $(p=1.000)$ dengan kepemilikan jamban di Desa Malikian, Mempawah Hilir.
\end{abstract}

Kata kunci : Jamban, penghasilan, pengetahuan, sikap. 


\section{Pendahuluan}

Penyediaan air bersih, pembuangan kotoran, pembuangan air limbah, dan pembuangan sampah merupakan syarat rumah sehat. Pembuangan kotoran/tinja, yang biasa juga di sebut dengan tempat Buang Air Besar (BAB) merupakan bagian yang penting dalam sanitasi lingkungan. Pembuangan tinja manusia yang tidak memenuhi syarat sanitasi dapat menyebabkan terjadinya pencemaran tanah serta penyediaan air bersih, dan memicu hewan vektor penyakit, misalnya lalat, tikus atau serangga lain untuk bersarang, berkembang biak serta menyebarkan penyakit. Hal tersebut juga tidak jarang dapat menyebabkan timbulnya bau yang tidak sedap. ${ }^{1}$

Wabah penyakit pada masyarakat akan meluas jika masih terjadi Buang Air Besar Sembarangan (BABS), misalnya $\mathrm{BAB}$ di kebun, sungai dan tempat lain yang kurang memenuhi syarat jamban sehat. ${ }^{2}$ Diare menempati urutan nomor satu, sebesar 72\%, prevalensi penyakit akibat sanitasi buruk. $^{3}$ Faktor agent, penjamu (host), lingkungan, pelayanan kesehatan, dan perilaku merupakan faktor-faktor yang berkaitan dengan kejadian diare pada balita. Tidak diberikannya ASI (Air Susu Ibu) eksklusif, kurang gizi, munculnya penyakit infeksius, keturunan, dan imunodefisiensi, menjadi faktor penjamu yang berakibat terjadinya kerentanan diare. Pembuangan tinja adalah satu diantara faktor lingkungan yang paling sering menyebabkan diare, yang kemudian dilanjutkan dengan kurangnya sarana air bersih, adanya vektor dan penanganan sampah. ${ }^{4}$

Hal tersebut mendukung dari hasil penelitian Darsana, ${ }^{5}$ yang menunjukkan bahwa selain faktor pendidikan dan pengetahuan mengenai sarana sanitasi, terdapat adanya hubungan yang bermakna antara kepemilikan jamban dengan kejadian diare, ditambah dengan faktor kondisi lingkungan serta perilaku (kebiasaan) masyarakat membuang kotoran. ${ }^{6}$ Begitu pula dengan peran petugas kesehatan sebagai penunjang pencegah kejadian Diare.

Mengutip dari CNN Indonesia tentang laporan Join Monitoring Program (JMP) WHO/Unicef, 7 ternyata masih terdapat $12,9 \%$ penduduk Indonesia yang belum memiliki jamban, dari 2,4 milliar penduduk dunia yang tidak memiliki jamban, dengan rasio tujuh dari sepuluh orang di dunia masih $\mathrm{BAB}$ di tempat terbuka, dimana sebagian besar adalah di sungai. Di Indonesia, kloset leher angsa yng digunakan 84,4\%, plengsengan $4,8 \%$, cemplung atau cubluk tanpa lantai $7,2 \%$, cemplung dengan lantai 3,7\%. Kalimantan Barat yang memiliki jamban sendiri 1263, jamban 
bersama 140, jamban umum 89, dan yang tidak punya jamban $617 .{ }^{8}$

Menurut data puskesmas Mempawah Hilir tahun 2014 dari 855 rumah yang dilakukan pemeriksaan sebanyak 530 rumah tangga, rumah tangga yang memiliki sarana sanitasi dasar berupa jamban di wilayah kerja Puskesmas Mempawah Hilir sebesar 420 rumah tangga atau $79 \%$ tetapi dengan sarana yang kurang memenuhi syarat kesehatan, terutama pembuangan air limbah. Hasil studi awal yang dilakukan sebelumnya pada 88 masyarakat desa Malikian, menunjukkan 36,4\% kondisi jamban yang ada di masyarakat tidak memenuhi syarat jamban sehat. ${ }^{9}$

Berdasarkan dari penjelasan latar belakang tersebut diatas, maka peneliti tertarik untuk mengatahui lebih lanjut tentang faktor determinan apa saja yang mempengaruhi kepemilikan jamban sehat di masyarakat desa Malikian, Mempawah Hilir, Kalimantan Barat.

\section{Metode Penelitian}

Penelitian ini dilakukan di desa Malikian Kecamatan Mempawah Hilir Kabupaten Mempawah Provinsi Kalimantan Barat yang terdiri dari 8 dusun dengan 27 RT/ 12 RW, pada tanggal April - Mei 2016, dengan menggunakan rancangan penelitian obeservasional deskriptif analitik dengan pendekatan Cross Sectional.

Populasi dalam penelitian ini adalah seluruh ibu yang mempunyai balita di desa Malikian Kecamatan Mempawah Hilir Kabupaten Mempawah Provinsi Kalimantan Barat sebanyak 327 orang. Jumlah sampel 64 orang dilakukan proporsional (purposive sampling) setiap Dusun dan penentuan sampel menggunakan random sampling pada balita. Instrumen yang digunakan untuk mengetahui dan meneliti adalah kuesioner yang berkaitan dengan karakteristik responden dan faktorfaktor yang mempengaruhi kepemilikan jamban sehat.

\section{Hasil Penelitian dan Pembahasan}

\section{Karakteristik Responden}

Tabel 1. Distribusi Frekuensi Balita Responden Berdasarkan Umur di Desa Malikian

\begin{tabular}{|c|c|c|c|}
\hline No & Umur & $F$ & $\%$ \\
\hline 1 & 20-30 tahun & 14 & 21.9 \\
\hline 2 & $31-40$ tahun & 18 & 28.1 \\
\hline 3 & 41-50 tahun & 17 & 26.6 \\
\hline \multirow[t]{2}{*}{4} & 51 tahun ke atas & 11 & 17.2 \\
\hline & Jumlah & 64 & 100 \\
\hline
\end{tabular}

Sumber: Data Primer Desa Malikian 2016 
Berdasarkan tabel 1, usia tersebut merupakan anggota keluarga, responden yang menarik untuk misalnya nenek, atau saudara dari dipaparkan adalah usia diatas 51 tahun orangtua yang mengasuh balita di rumah ke atas, sebanyak 17,2\%. Responden ketika ibu balita sedang bekerja.

\section{Analisis Univariat}

Tabel 2. Distribusi Frekuensi Responden Berdasarkan Kepemilikan Jamban di Desa Malikian

\begin{tabular}{cccc}
\hline No & Kepemilikan jamban & Frekuensi & Persen (\%) \\
\hline 1 & Ya & 24 & 37.5 \\
2 & Tidak & 40 & 62.5 \\
\hline & Jumlah & 64 & 100 \\
\hline
\end{tabular}

Sumber: Data Primer Desa Malikian 2016

Tabel 3. Distribusi Frekuensi Responden Berdasarkan Tingkat Pengetahuan di Desa Malikian

\begin{tabular}{cccc}
\hline No & Pengetahuan & Frekuensi & Persen (\%) \\
\hline 1 & Kurang baik & 16 & 25.0 \\
2 & Baik & 48 & 75.0 \\
\hline & Jumlah & 64 & 100 \\
\hline
\end{tabular}

Sumber: Data Primer Desa Malikian 2016

Tabel 4. Distribusi Frekuensi Responden Berdasarkan Sikap di Desa Malikian

\begin{tabular}{cccc}
\hline No & Sikap & Frekuensi & Persen (\%) \\
\hline 1 & Kurang baik & 23 & 35.9 \\
2 & baik & 41 & 64.1 \\
\hline & Jumlah & 64 & 100 \\
\hline
\end{tabular}

Sumber: Data Primer Desa Malikian 2016

Tabel 5. Distribusi dan Frekuensi Penyuluhan di Desa Malikian

\begin{tabular}{clcc}
\hline No & Penyuluhan Kesehatan & Frekuensi & Persen (\%) \\
\hline 1 & Ada Penyuluhan & 9 & 14.1 \\
2 & Tidak ada penyuluhan & 55 & 85.9 \\
\hline & Jumlah & 64 & 100 \\
\hline
\end{tabular}

Sumber: Data Primer Desa Malikian 2016

\section{Analisis Bivariat}

\section{Hubungan Pendidikan dengan Kepemilikan Jamban}

Pada penelitian sebelumnya yang dilakukan oleh Vivi Maya Sari pada tahun 2012 dipemukiman nelayan Kenagarian Air Bangis Kec. Sungai Beremas Kab.
Pasaman Barat. Secara statistik dibuktikan bahwa tidak ada hubungan yang bermakna antara pendidikan 
dengan kepemilikan jamban keluarga (JAGA). ${ }^{10}$

Tabel 6. Hubungan Pendidikan dengan Kepemilikan Jamban di Desa Malikian 2016

\begin{tabular}{|c|c|c|c|c|c|c|}
\hline \multirow[t]{3}{*}{ Pendidikan } & \multicolumn{4}{|c|}{ Kepemilikan jamban } & \multirow[t]{2}{*}{ P Value } & \multirow{2}{*}{$\begin{array}{c}\text { PR } \\
\text { (CI 95\%) }\end{array}$} \\
\hline & \multicolumn{2}{|c|}{$\mathrm{Ya}$} & \multicolumn{2}{|c|}{ Tidak } & & \\
\hline & $\mathrm{N}$ & $(\%)$ & $\mathrm{N}$ & $(\%)$ & 0.196 & 2.692 \\
\hline Rendah & 26 & 65.0 & 20 & 83.3 & & $(0.768-9.442)$ \\
\hline Tinggi & 14 & 35.0 & 4 & 16.7 & & \\
\hline Jumlah & 40 & 100 & 24 & 100 & & \\
\hline
\end{tabular}

Sumber : Data Primer Desa Malikian 2016

Berdasarkan tabel diatas, kepemilikan jamban pada balita dengan pendidikan rendah yang memiliki $\quad p$ value $=0,196$. Pendidikan yang rendah jamban yaitu sebesar $65.0 \%$ dan berisiko 2.692 kali lebih besar tidak pendidikan tinggi yang memiliki jamban memiliki jamban dibandingkan dengan sebesar 35.0\%. Hasil uji statistik dengan menggunakan uji Chi-square dinyatakan bahwa tidak terdapat hubungan yang bermakna antara pengetahuan dengan pendidikan tinggi. Maka hasil tersebut diatas, menggarisbawahi apa yang sudah disampaikan oleh Vivi (2012) tersebut diatas.

\section{Hubungan Penghasilan dengan kepemilikan jamban}

Tabel 7. Hubungan penghasilan dengan kepemilikan jamban di Desa Malikian tahun 2016

\begin{tabular}{|c|c|c|c|c|c|c|}
\hline \multirow[t]{3}{*}{ Penghasilan } & \multicolumn{4}{|c|}{ Diare } & \multirow[t]{2}{*}{ P Value } & \multirow{2}{*}{$\begin{array}{c}\text { PR } \\
\text { (CI 95\%) }\end{array}$} \\
\hline & \multicolumn{2}{|c|}{ Ya } & \multicolumn{2}{|c|}{ Tidak } & & \\
\hline & $\mathrm{N}$ & $(\%)$ & $\mathrm{N}$ & $(\%)$ & 0.037 & 3.667 \\
\hline Rendah & 18 & 45.0 & 18 & 75.0 & & $(1.203-11.174)$ \\
\hline Tinggi & 22 & 55.0 & 6 & 25.0 & & \\
\hline Jumlah & 40 & 100 & 24 & 100 & & \\
\hline
\end{tabular}

Sumber : Data Primer Desa Malikian 2016

Berdasarkan tabel diatas, dengan kepemilikan jamban pada balita penghasilan rendah yang memiliki dengan $p$ value $=0,037$. Penghasilan jamban sebesar $45.0 \%$ dan penghasilan tinggi yang memiliki jamban sebesar rendah berisiko 3.667 kali tidak memiliki jamban dibandingkan dengan 55.0\%. Hasil uji statistik dengan penghasilan tinggi yang tidak memiliki menggunakan uji Chi-square dinyatakan bahwa terdapat hubungan yang jamban. Status ekonomi seseorang juga bermakna antara penghasilan rendah akan menentukan tersedianya suatu fasilitas yang diperlukan untuk kegiatan 
tertentu, sehingga status sosial ekonomi ini akan mempengaruhi perubahan perilaku pada diri seseorang.

Berdasarkan hasil penelitian yang dilakukan oleh Darsana pada tahun 2014 di Desa Jehem Kec. Tembuku Kab. Bangli, secara statistik dibuktikan bahwa ada hubungan yang bermakna antara ekonomi dengan kepemilikan jamban keluarga $\rho=0,000<\alpha(0,05) \cdot{ }^{5}$ Dengan demikian dapat disimpulkan dari hasil penelitian yang dilakukan oleh peneliti bahwa ekonomi merupakan alat ukur tingkat kesejahteraan suatu masyarakat. Karena ekonomi merupakan indikator penentu perilaku masyarakat dalam pemenuhan kebutuhan sehari - hari termasuk pemanfaatan jamban keluarga (JAGA).11

\section{Hubungan pengetahuan dengan kepemilikan jamban}

Tabel 7. Hubungan pengetahuan dengan kepemilikan jamban di Desa Malikian tahun 2016

\begin{tabular}{ccccccc}
\hline Pengetahuan & \multicolumn{4}{c}{ Kepemilikan jamban } & P Value & PR \\
\cline { 2 - 5 } & \multicolumn{2}{c}{ Ya } & \multicolumn{2}{c}{ Tidak } & & (CI 95\%) \\
\cline { 2 - 5 } & $\mathrm{N}$ & $(\%)$ & $\mathrm{N}$ & $(\%)$ & 0,037 & 0.169 \\
\hline Kurang baik & 14 & 35.0 & 2 & 8.3 & & $(0.035-0.825)$ \\
\hline Baik & 26 & 65.0 & 22 & 91.7 & & \\
\hline Jumlah & 40 & 100 & 24 & 100 & & \\
\hline
\end{tabular}

Sumber : Data Primer Desa Malikian 2016

Berdasarkan tabel diatas, pengetahuan yang baik pun hanya $65 \%$ responden yang memiliki jamban. Sebaliknya, dari responden yang tidak memiliki jamban, ternyata terdapat $91,7 \%$ responden yang baik pengetahuannya.

$$
\text { Hasil uji statistik dengan }
$$
menggunakan uji Chi-square dinyatakan bahwa terdapat hubungan yang bermakna antara pengetahuan baik dengan kepemilikan jamban pada balita dengan $p$ value $=0,037$. Pengetahuan kurang baik berisiko 0,169 kali tidak memiliki jamban dibandingkan dengan pengetahuan baik yang tidak memiliki jamban.

Pengetahuan merupakan hasil "tahu" penginderaan manusia terhadap suatu objek tertentu. Proses penginderaan terjadi melalui panca indera manusia, yakni penglihatan, pendengaran, penciuman, rasa dan melalui kulit. Pengetahuan atau kognitif merupakan domain yang sangat penting untuk terbentuknya tindakan seseorang (over behavior). ${ }^{12}$

$$
\text { Berdasarkan hasil penelitian }
$$
yang dilakukan oleh Ikhsan Ibrahim pada tahun 2012 di Desa Pintu Langit Jae Kec. Padang Sidimpuan Angkola Julu. Secara 
statistik dibuktikan bahwa ada hubungan yang bermakna antara pengetahuan dengan pemanfaatan jamban $\rho=0,000<$ $\alpha(0,05) \cdot{ }^{13}$

Dengan demikian dapat disimpulkan dari hasil penelitian yang dilakukan oleh peneliti bahwa
Pemanfaatan Jamban Keluarga (JAGA) oleh masyarakat dengan pengetahuan yang cukup memiliki kemampuan dalam memanfaatkan jamban keluarga (JAGA) dibanding dengan masyarakat dengan pengetahuan yang kurang

\section{Hubungan sikap dengan kepemilikan jamban}

Tabel 8. Hubungan Sikap dengan Kepemilikan Jamban di Desa Malikian 2016

\begin{tabular}{ccccccc}
\hline sikap & \multicolumn{3}{c}{ Kepemilikan jamban } & P Value & PR \\
\cline { 2 - 5 } & \multicolumn{2}{c}{ Ya } & \multicolumn{2}{c}{ Tidak } & & (CI 95\%) \\
\cline { 2 - 5 } & $\mathrm{N}$ & $(\%)$ & $\mathrm{N}$ & $(\%)$ & 0,037 & 3.545 \\
& 10 & 25.0 & 13 & 54.2 & & $(1.209-10.394)$ \\
\hline Kurang baik & 30 & 75.0 & 11 & 45.8 & & \\
\hline baik & 40 & 100 & 24 & 100 & & \\
\hline Jumlah & 40 & &
\end{tabular}

Sumber : Data Primer Desa Malikian 2016

Berdasarkan tabel diatas, sikap kurang baik yang memiliki jamban sebesar $25.0 \%$ dan pengetahuan baik yang memiliki jamban sebesar $75.0 \%$. Hasil uji statistik dengan menggunakan uji Chi-square dinyatakan bahwa terdapat hubungan yang bermakna antara sikap kurang baik dengan kepemilikan jamban pada balita dengan $p$ value $=0,037$. Sikap kurang baik berisiko 3.545 kali tidak memiliki jamban dibandingkan dengan sikap baik yang tidak memiliki jamban.

Sikap merupakan kesiapan untuk bereaksi terhadap suatu objek dengan cara - cara tertentu. Kesiapan yang dimaksud disini adalah kecenderungan potensial untuk bereaksi dengan cara tertentu apabila individu dihadapkan pada stimulus yang menghendaki adanya respons (Azwar, 2008). ${ }^{13}$ Berdasarkan hasil penelitian yang dilakukan oleh Ikhsan Ibrahim pada tahun 2012 di Desa Pintu Langit Jae Kec. Padang Sidimpuan Angkola Julu. Secara statistik dibuktikan bahwa ada hubungan yang bermakna antara sikap dengan pemanfaatan jamban $\rho=0,000<\alpha(0,05) \cdot{ }^{12}$

Dengan demikian dapat disimpulkan dari hasil penelitian yang dilakukan oleh peneliti bahwa sikap positif masyarakat terhadap masalah kesehatan sangat besar pengaruhnya terhadap perilaku masyarakat dalam pemanfaatan jamban keluarga (JAGA). 


\section{Hubungan peran petugas kesehatan dengan kepemilikan jamban}

Tabel 9. Hubungan peran petugas kesehatan dengan kepemilikan jamban Desa Malikian tahun 2016

\begin{tabular}{|c|c|c|c|c|c|c|}
\hline \multirow{3}{*}{$\begin{array}{l}\text { Peran petugas } \\
\text { kesehatan }\end{array}$} & \multicolumn{4}{|c|}{ Kepemilikan jamban } & \multirow[t]{3}{*}{$P$ Value } & \multirow{3}{*}{$\begin{array}{c}\text { PR } \\
\text { (CI 95\%) }\end{array}$} \\
\hline & \multicolumn{2}{|c|}{ Diare } & \multicolumn{2}{|c|}{ Tidak } & & \\
\hline & $\mathrm{N}$ & $(\%)$ & $\mathrm{N}$ & $(\%)$ & & \\
\hline $\begin{array}{l}\text { Tidak mendapat } \\
\text { penyuluhan }\end{array}$ & 34 & 85.0 & 21 & 87.5 & 1.000 & $\begin{array}{c}1.235 \\
(0.279-5.475)\end{array}$ \\
\hline $\begin{array}{c}\text { Mendapat } \\
\text { penyuluhan }\end{array}$ & 6 & 15.0 & 3 & 12.5 & & \\
\hline Jumlah & 40 & 100 & 24 & 100 & & \\
\hline
\end{tabular}

Sumber : data Primer Desa Malikian 2016

Berdasarkan tabel diatas, peran

tidak mendapat penyuluhan dan memiliki jamban sebesar $85.0 \%$ dan mendapat penyuluhan yang memiliki jamban sebesar $15.0 \%$. Hasil uji statistik dengan menggunakan uji Chi-square dinyatakan bahwa tidak terdapat hubungan yang bermakna antara tidak mendapat penyuluhan dengan kepemilikan jamban pada balita dengan $p$ value $=1.000$. tidak mendapat penyuluhan berisiko 1.235 kali tidak memiliki jamban dibandingkan dengan yang mendapat penyuluhan.

Petugas kesehatan merupakan setiap orang yang mengabdikan diri dalam bidang kesehatan serta memiliki pengetahuan dan/atau keterampilan

\section{Kesimpulan dan Saran}

Berdasarkan hasil analisa statistik, maka dapat disimpulkan faktor determinan yang berpengaruh terhadap kepemilikan jamban di Desa Malikian adalah sebagai berikut: melalui pendidikan di bidang kesehatan yang untuk jenis tertentu memerlukan kewenangan untuk melakukan upaya kesehatan. Salah satu unsur yang berperan dalam percepatan pembangunan kesehatan adalah tenaga kesehatan yang bertugas di sarana pelayanan kesehatan dimasyarakat

Hal ini tidak sejalan dengan hasil penelitian yang dilakukan oleh Darsana pada tahun 2014 di Desa Jehem Kec. Tembuku Kab. Bangli. Secara statistik dibuktikan bahwa ada hubungan yang bermakna antara peranan petugas kesehatan dengan kepemilikan jamban keluarga $\rho=0,01<\alpha(0,05) .^{5}$

1. Hasil survei penentuan faktor determinan menyatakan tidak terdapat hubungan antara pendidikan dengan kepemilikan jamban pada balita $(\mathrm{p}$ value $=$ 
0,196). Dan berdasarkan hasil uji chi-square PR $=2.692$.

2. Hasil survei penentuan faktor determinan menyatakan terdapat hubungan antara penghasilan dengan kepemilikan jamban pada balita $(\mathrm{p}$ value $=$ 0,037). Dan berdasarkan hasil chi-square $\mathrm{PR}=3.667$

3. Hasil survei penentuan faktor determinan menyatakan terdapat hubungan antara pengetahuan dengan kepemilikan jamban pada balita ( $\mathrm{p}$ value $=0,037)$. Dan berdasarkan hasil chi-square PR $=0.169$

4. Hasil survei penentuan faktor determinan menyatakan terdapat hubungan antara sikap dengan kepemilikan jamban pada balita $(\mathrm{p}$ value $=0,037)$. Dan berdasarkan hasil chi-square PR $=3.545$

5. Hasil survei penentuan faktor determinan menyatakan tidak terdapat hubungan antara peran petugas kesehatan dengan kepemilikan jamban pada balita ( $\mathrm{p}$ value $=1.000)$. Dan berdasarkan hasil chi-square PR $=1.235$
Kepemilikan jamban di desa Malikian, Kecamatan Mempawah Hilir, Kabupaten Mempawah, Kalimantan Barat masih membutuhkan banyak perhatian dari pemerintah. Sebagian besar masyarakat yang ada mempunyai jamban, ternyata masih banyak yang tidak memenuhi syarat jamban sehat yaitu dengan menggali tanah sebagai jamban, dan sisanya tidak mempunyai jamban atau BAB di sungai.

Oleh karena kesimpulan diatas, maka saran bagi petugas kesehatan, meski dari hasil analisis tidak terdapt hubungan antara peran petugas atau adanya penyuluhan di wilayah tersebut, akan tetapi peran petugas lebih digiatkan, misalnya dengan kegiatan penyuluhan kesehatan tentang jamban sehat, manfaat jamban sehat, akibat BABS, dan bagaimana membangun jamban sehat dengan mempromosikan Arisan Jamban Sehat. Pemasangan poster tentang bahaya BABS, manfaat pentingnya memiliki jamban sehat, dan membagikan brosur program Arisan Jamban Sehat, berikut dengan membentuk para kader di desa sehingga bisa mengoptimalkan upaya peningkatan derajat kesehatan masyarakat di desa oleh para petugas bersama dengan masyarakat. 


\section{DAFTAR PUSTAKA}

1. Putranti, Dya CMS, dkk. 2013. Hubungan Antara Kepemilikan Jamban dengan Kejadian Diare di Desa Karangagung Kecamatan Palang Kabupaten Tuban. Diakses 7 April 2016 pada URL : http://www.journal.unair.ac.id/filer PDF/keslingb03cb54364full.pdf

2. Erlina. 2015. Faktor yang Berhubungan dengan PHBS pada Tatanan Rumah Tangga Menggunakan Jamban Sehat. Jurnal Ilmiah Keperawatan STIKes-Medika. Cikarang. vol.5, No.1.

3. WSP-EAP. 2008. Economic Impacts of Sanitation in Indonesia. Research Report. 21 - 30.

4. Wijaya, Yulianto. Faktor Risiko Kejadian Diare Balita Di Sekitar Tps Banaran Kampus Unnes. Unnes Journal of Public Health. Diakses pada tanggal 20 April 2016 pada URL :

http://journal.unnes.ac.id/sju/index .php/ujph/article/view/3050

5. Darsana, I Nengah. 2014. Faktor Yang Berhubungan Dengan Kepemilikan Jamban Keluarga. Jurnal Kesehatan Lingkungan. Diakses pada tanggal 20 April 2016 pada URL : http://poltekkesdenpasar.ac.id/files/JURNAL\%20KES EHATAN\%20LINGKUNGAN/V4N2/I \%20Nengah\%20Darsana1,\%20I\%20 Made\%20Bulda\%20Mahayana2,\%20 I\%20Made\%20Patra3.pdf

6. Zainiyah, Alif N, dkk. 2013. Hubungan kepemilikan Jamban dengan Tingkat Pengetahuan dan Pendidikan Masyarakat (Studi di Desa Mendalan Kecamatan Winongan Kabupaten Pasuruan Tahun 2013) (online), diambil dari http://digilib.poltekkesdepkessby.ac.id/public/POLTEKKESSBYPublication-529AlifNurilSriMardoyo.pdf, diakses pada tanggal 6 April2016.

7. WHO/Unicef. 2015. 25 Years Progress on Sanitation and Drinking Water. http://www.depkes.go.id/resources /download/general/Hasil\%20Riske sdas\%202013.pdf . (online). diakses pada tanggal 6 April 2016.

8. Riskesda, 2013.

http://www.depkes.go.id/resources /download/general/Hasil\%20Riske sdas\%202013.pdf . (online). diakses pada tanggal 6 April 2016.

9. Mempawah Hilir. 2014. Laporan Bulanan Puskesmas Mempawah Hilir

10. Vivi maya sari .2012. Faktor Yang Berhubungan Dengan Pemanfaatan Jamban Community Letd Total Sanitation (CLTS) Di Kenagarian Kurnia Selatan Kecamatan Sungai Rumbai Kabupaten Dharmasraya. Diakses pada tanggal 8 April 2016 pada URL :

http://repository.unand.ac.id/2004 0/1/Jurnal\%20ku.pdf

11. Notoatmodjo. 2007. Kesehatan Masyarakat Ilmu dan Seni. Rineka Cipta, Jakarta.

12. Ibrahim, Ikhsan, dkk. 2012. FaktorFaktor Yang Berhubungan Dngan Pemanfaatan Jamban Di Desa Pintu Langit Jae Kecamatan Padangsimpuan Angkola Julu. Diakses pada tanggal 22 April 2016 pada URL :

http://download.portalgaruda.org/a rticle.php?article $=110065 \& \mathrm{val}=411$ 0\&title $=$ FAKTOR-

FAKTOR\%20YANG\%20BERHUBUN GAN\%20DENGAN\%20PEMANFAAT AN\%20\%20JAMBAN\%20DI\%20DES A\%20PINTU\%20LANGIT\%20JAE\%2 OKECAMATAN\%20\%20PADANGSID IMPUAN\%20ANGKOLA\%20JULU\%2 0\%20\%20TAHUN\%202012.

13. Azwar, S. 2008. Sikap Manusia Teori dan Pengukurannya. Yogyakarta: Liberty. 